\title{
Crescimento, Dominância Continuadae Declínio daEmpresa: Insights das Histórias da General Electric e da Westinghouse
}

\author{
Denise L. Fleck
}

\section{Resumo}

Este artigo compara as trajetórias de crescimento da General Electric e da Westinghouse por mais de doze décadas. Enquanto a General Electric desfrutou crescimento e existência continuados, a Westinghouse cresceu, mas também sofreu contração por três décadas e desapareceu após 110 anos de existência. A análise comparativa revelou que, afora as capacitações comparáveis no desenvolvimento de alta tecnologia, as duas empresas diferiam em vários aspectos. Elas desempenharam papéis desiguais na estruturação do setor elétrico e enfrentaram os desafios do aumento do tamanho de maneiras bem distintas. A análise histórica indica que a General Electric tendeu a desenvolver capacitações gerenciais que aumentaram suas chances de perpetuar-se. Já a Westinghouse, durante a maior parte do tempo, desenvolveu propensão à autodestruição.

Palavras-chaves: crescimento da firma; longevidade organizacional; traços organizacionais; estudo histórico; indústria elétrica norte-americana.

\section{Abstract}

The paper compares the growth trajectories of General Electric and Westinghouse during twelve decennia. While General Electric has enjoyed a continuing growth and a continued existence, Westinghouse grew but also experienced a three-decades long contraction and disappeared after 110 years of existence. The comparative analysis has revealed that apart from comparable capabilities in the development of high technology, the two firms differed in several respects. They played different roles in the structuring of the electrical industry and faced the challenges of increasing size in very distinct ways. Historical analysis suggests that General Electric has tended to develop managerial capabilities that have enhanced its chances of becoming self-perpetuating. Westinghouse, on the other hand, more often than not developed certain propensity for self-destruction.

Key words: corporate growth; organizational longevity; organizational traits; historical study; American electrical industry. 


\section{INTRODUÇÃo}

Compreender o sucesso e o fracasso das organizações tem sido preocupação central dos estudos organizacionais. Carece-se, no entanto, de uma definição de sucesso. Alguns associam sucesso a crescimento organizacional, endossando o imperativo “Crescer ou Morrer!”. O crescimento, porém, não pode ser indicador confiável do sucesso, porque muitas empresas crescem e morrem depois. Outros, como Barnard (1938), sustentam que a capacidade da empresa de sobreviver constitui o único indicador verdadeiro de seu sucesso, mas isso requer que se consiga distinguir existência bem-sucedida de mera subsistência.

Este artigo sugere que a sobrevivência deve ser vista como propriedade dinâmica da empresa. As chances de a empresa desenvolver uma existência continuada podem variar ao longo do tempo, na medida em que aumenta ou diminui sua propensão a se perpetuar. Este artigo explora a perspicaz, porém pouco elaborada noção de autoperpetuação da empresa (Chandler, 1977). Segundo Chandler (1977), uma vez estabelecidas uma hierarquia gerencial e uma eficiente coordenação administrativa de recursos, instalações e habilidades, torna-se autoperpetuante a empresa moderna.

A realização de estudos complementares das observações de Chandler (1977) sobre o crescimento tem sido sugerida. Na visão de Scherer (1990), as pesquisas devem buscar explicações mais profundas para posições persistentemente mantidas de dominância setorial. De forma análoga, Kocka (1990, p. 715) assinala que "talvez se devam fornecer mais explicações acerca dos motivos pelos quais histórias de sucesso inicial tantas vezes se transformaram em histórias de declínio e fracasso".

O estudo aqui apresentado examinou doze décadas na existência da General Electric (GE), empresa que manteve persistentemente posições de dominância setorial, e da Westinghouse (WH), uma história de inquestionável sucesso inicial que se transformou em declínio. Pioneiras em muitos negócios de base tecnológica, estas empresas eletrificaram cidades, dotaram-nas de iluminação, produziram milhares de bens de consumo, foram pioneiras em eletrônica e telecomunicações. Além de inventar e fabricar, partiram para o marketing, distribuição e finanças, tendo-se diversificado funcional e tecnologicamente. Para desenvolver produtos e sistemas cada vez mais complexos, estenderam seus conhecimentos aos campos elétrico, mecânico, químico e nuclear. Com isso, ambas as empresas experimentaram períodos de crescimento continuado, 
atingindo tamanhos colossais. De fato, desde que a relação das 500 maiores empresas da Fortune passou a ser publicada, ambas as empresas figuraram entre as 30 maiores norte-americanas. Em 1997, porém, os negócios da WH foram cindidos e a empresa de 110 anos deixou de existir. Àquela altura, a WH caíra para a 135ª posição na lista da Fortune de 1996.

As trajetórias de crescimento das duas empresas, em seus últimos 80 anos, são mostradas na Figura 1. O indicador de tamanho usado é obtido calculando-se as vendas totais como porcentagem do PNB norte-americano. O indicador não muda no tempo, produzindo um valor adimensional, com ajuste automático das mudanças inflacionárias e deflacionárias no valor da moeda, aspecto importante em análises longitudinais.

\section{Figura 1: Trajetórias de Crescimento da General Electric e da Westinghouse}

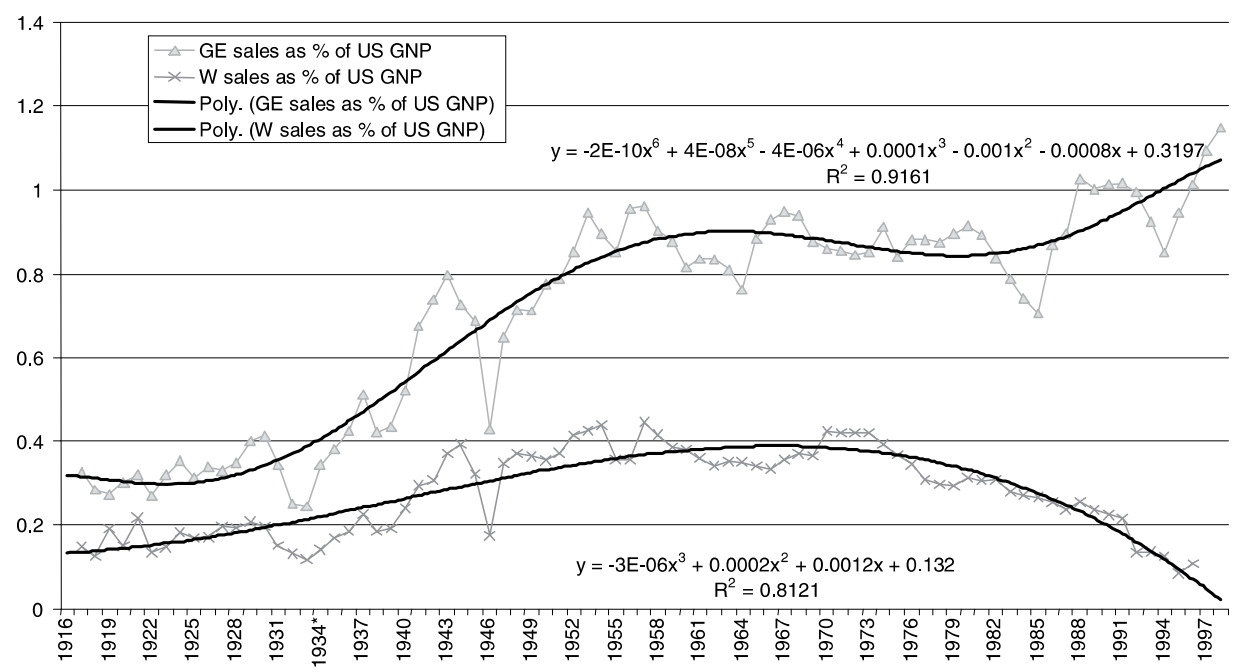

Essencialmente, a GE seguiu uma trajetória ascendente. A sua participação na economia norte-americana cresceu de $0,37 \%$, em 1917 , para $1,14 \%$ em 1998 . A trajetória da WH, por outro lado, começou a declinar no final da década de 1950. Em 1917, o tamanho de seus negócios correspondia a 0,14\% do PNB norteamericano, aumentou para 0,44\% em 1957 e caiu para 0,10\% em 1996. Curiosamente, por várias décadas, as duas empresas descreveram uma trajetória sincronizada. Até a década de 1950, ambas concorriam basicamente nos mesmos negócios e mercados, enfrentando essencialmente o mesmo ambiente: duas guerras mundiais, altos e baixos da economia, incluindo a Grande Depressão, legislação e processos antitruste, atividade sindical e mudança de regimes tecnológicos. A partir da década de 1950, essa notável semelhança foi aos poucos 
desaparecendo. Ambas aceleraram gradualmente sua diversificação para outros negócios. A GE cresceu predominantemente a partir de sua base de conhecimentos tecnológicos, tornando-se uma empresa altamente diversificada em tecnologia. Já a WH transformou-se em conglomerado de negócios pouco relacionados.

As semelhanças nos negócios, mercados e ambiente até o final da década de 1950 sugerem comportamento imitativo e isomorfo. Uma explicação possível para essa trajetória sincronizada sustentaria que as empresas teriam cultivado inúmeras semelhanças até então. Depois disso, teriam mudado para enfrentar os novos desafios do mundo pós-Segunda Guerra Mundial. Imitação e isomorfismo teriam cessado, extinguindo o sincronismo das trajetórias. A mudança da GE teria tido mais êxito do que a da WH. O sucesso da GE e o fracasso da WH na adaptação à nova ordem explicaria os distintos destinos.

Essa explicação é apenas em parte verdadeira. A análise comparativa das histórias da GE e da WH indicou que, desde a sua criação e através de suas existências, as duas empresas diferiram muito entre si. Cada uma desenvolveu um conjunto de comporamentos persistentes ao longo do tempo, aqui denominados traços organizacionais. Quase sempre diametralmente opostos, esses traços ajudam a explicar seus diferentes destinos. Enquanto os traços da GE contribuíram para o desenvolvimento de propensão à autoperpetuação, os da WH promoveram uma propensão à autodestruição.

As histórias dessas empresas inspiram uma questão mais geral: como e por que certas empresas desfrutam de crescimento e existência continuados, enquanto outras acabam contraindo-se e, com o tempo, desaparecendo? A análise comparativa das histórias dessas duas empresas procurou, portanto, identificar as condições que promovem o desenvolvimento da propensão organizacional à autoperpetuação e aquelas que, impedindo a autoperpetuação, acabam promovendo a propensão organizacional à autodestruição.

Este artigo está organizado em quatro partes principais. Os fundamentos teóricos são apresentados primeiro; em seguida, é descrito o método de pesquisa; depois, são identificados períodos da história do setor elétrico norte-americano; finalmente, são apresentados os traços organizacionais das duas empresas. Uma seção conclusiva encerra o artigo.

\section{Fundamentos Teóricos}

Como as empresas obtêm e sustentam a vantagem competitiva? Essa tem sido 
considerada a pergunta fundamental do campo da gestão estratégica (Teece, Pisano e Shuen, 1997). Acredita-se que a vantagem competitiva explique o desempenho excepcional de uma empresa e, portanto, possibilite o seu crescimento. Várias perspectivas têm sido usadas para examinar as origens da vantagem competitiva. Enquanto analistas da indústria (Porter, 1980) examinam a estrutura da indústria em certo ponto do tempo, a visão baseada nos recursos (Barney, 1997) identifica recursos específicos da empresa e o modelo das capacitações dinâmicas (Teece, Pisano e Shuen, 1997; Eisenhardt e Martin, 2000) explica a criação de valor em ambientes acelerados. Tais perspectivas complementares indicam que vários fatores contribuem para o desenvolvimento da vantagem competitiva: o correto posicionamento da firma em uma indústria, a posse e uso de recursos valiosos, raros e difíceis de imitar, e o desenvolvimento de processos gerenciais e organizacionais moldados pelos ativos específicos da empresa e pelas trajetórias disponíveis.

Por mais esclarecedoras que sejam essas explicações, é preciso ir além da análise da vantagem competitiva para explicar sucesso e fracasso organizacionais de empresas longevas. Como afirmou Porter (1987), a concorrência ocorre no nível dos negócios, em que gerentes se engajam em batalhas no mercado contra empresas rivais. Já no nível corporativo, à medida que as empresas crescem, os gestores enfrentam os desafios de gerir organizações mais diversificadas, complexas e desunidas em ambiente heterogêneo e mutável. Estes aspectos complementares — organizacional e relacionado aos negócios — são abordados a seguir.

\section{Aspectos dos Negócios no Sucesso e Fracasso de Longo Prazo}

O desempenho econômico excepcional de uma empresa, sem dúvida, contribui para a sua propensão a continuar a existir, porque, em princípio, as aspirações de todos os envolvidos (stakeholders) podem ser supostamente satisfeitas. Tal desempenho consegue eliminar ou adiar planos de descartar a organização ou algumas partes dela. Por exemplo, na década de 1980, a GE adquiriu a RCA que incluía a rede de televisão NBC. Essa rede era candidata ao descarte; porém, devido a seu desempenho superior, a GE manteve a NBC.

Segundo a literatura sobre organização industrial, o desempenho da empresa depende da pressão exercida pelas forças competitivas sobre a rentabilidade dos protagonistas do setor. A empresa obtém desempenho superior posicionando-se de forma a explorar o poder do mercado.

Na visão de Barney (1997, p. 33), uma empresa exibe desempenho acima do normal sempre que ela "gera com seus recursos um valor econômico superior ao 
que os proprietários desses recursos esperam”. Dada a improbabilidade de que a mera sorte possa impulsionar desempenho excepcional sustentado, a gestão competente dos recursos, habilidades e capacitações tem sido amplamente prescrita na literatura (Andrews, 1965; Penrose, 1980; Barney, 1997). O esquema VRIO de análise de recursos (Barney, 1997) sustenta que explorar um recurso Valioso, Raro e caro de Imitar gera desempenho econômico acima do normal e vantagem competitiva sustentada, se a firma dispuser de capacitações Organizacionais para explorar esses recursos. A capacidade da empresa de explorar recursos VRIO constitui, portanto, requisito para a empresa obter vantagem competitiva sustentada, ou seja, desempenho excepcional.

Nos ambientes em rápida mudança, porém, como sustentam Eisenhardt e Martin (2000), a visão baseada nos recursos "atinge uma condição de limite". O que explica o desempenho superior de uma empresa é o desenvolvimento de capacitações dinâmicas - processos da empresa que integram, reconfiguram, capturam e liberam recursos para rapidamente acompanhar e criar mudanças no mercado. Segundo o esquema das capacitações dinâmicas (Teece, Pisano e Shuen, 1997, p. 524), a essência da competência e capacitações dinâmicas "reside nos processos organizacionais da empresa, que são, por sua vez, moldados pelos ativos da empresa [posições] e sua trajetória evolucionária. [...] O que a empresa pode fazer costuma estar até certo ponto limitado por suas posições e trajetórias”.

Pode-se, portanto, dizer que o sucesso de longo prazo nos negócios requer o desenvolvimento de duas habilidades que conduzem ao desempenho excepcional. A primeira diz respeito à capacidade da empresa de exercer prolongado poder no mercado, ocupando posição privilegiada no setor. A segunda habilidade diz respeito à capacidade da empresa de projetar processos organizacionais que lhe permitam capturar, explorar e reconfigurar recursos valiosos e moldar consideravelmente seu ambiente de negócios.

\section{Aspectos Organizacionais no Sucessoe Fracasso de Longo Prazo}

Na visão de Barnard (1938), a cooperação bem-sucedida constitui importante desafio gerencial. Ele afirma que poucas organizações sobrevivem, porque tal cooperação nas organizações constitui a exceção. A norma na história humana, segundo ele, é o fracasso da cooperação, a desorganização, a desintegração e a destruição da organização.

Para Selznick (1957) a rivalidade organizacional pode ser o mais importante e perene problema na vida organizacional, por ameaçar a unidade do todo. A falta de cooperação e a rivalidade mal gerida podem provocar o desmantelamento e desaparecimento da organização. Em empresas grandes e diversificadas, a 
gerência precisa concentrar-se não apenas em desenvolver a vantagem competitiva das unidades de negócios, mas também em tornar o todo mais valioso que a soma das partes (Porter, 1987) e em impedir que a empresa se desintegre.

Em seus estudos do crescimento e da dominância continuada da empresa moderna, Chandler (1977) apresentou a noção da autoperpetuação das empresas. Ele sugeriu que, para tornar-se grande, a empresa precisava desenvolver eficiente coordenação administrativa do fluxo de recursos, em setores que oferecessem o maior potencial para tal coordenação. Em contraste com a firma tradicional, quase sempre efêmera, com uma única atividade econômica e dirigida por pequeno número de proprietários, a empresa moderna tornou-se autoperpetuante uma vez "estabelecida uma hierarquia gerencial e instalada uma coordenação administrativa eficiente do fluxo de materiais" (Chandler, 1977, p. 369). Os estudos históricos de Chandler $(1977,1990)$ sobre a ascensão e o crescimento da empresa moderna fornecem explicações trans-históricas para a ascensão, o crescimento e a existência continuada de empresas (Fleck, 2003). Constituem condições necessárias para o crescimento, sustentação de posição competitiva e autoperpetuação da empresa: o estabelecimento e cultivo de uma hierarquia gerencial; a coordenação administrativa de recursos, instalações e habilidades, possibilitando a geração de economias de escala e escopo; e o tríplice investimento em fabricação, marketing e gestão, à frente dos concorrentes. Tais condições permitem à empresa experimentar um processo de crescimento sustentado, criando novas oportunidades de expansão por meio da diversificação relacionada e impulsionada pela disponibilidade de recursos e habilidades subutilizados e transferíveis. Chandler (1977) também sugere que motivações produtivas para a expansão tendem a promover o crescimento sustentado, mais do que motivações defensivas.

Na visão de Penrose (1980, p. 85), "serviços produtivos não-utilizados constituem, para a empresa empreendedora, desafio para inovar, incentivo para se expandir e fonte de vantagem competitiva”. Penrose (1980) sustenta que empresas não-empreendedoras cessam de se expandir com o declínio das oportunidades e condições favoráveis. Já a empresa empreendedora, "se for de grande porte, alocará permanentemente partes de seus recursos à tarefa de investigar possíveis avenidas de expansão rentável” (Penrose, 1980, p. 34). Com o crescimento constante, a empresa tende a experimentar a renovação organizacional, a evitar a estagnação e a cultivar sua propensão a se perpetuar.

As obras históricas de Chandler (1977, 1990), porque visavam a entender a ascensão e crescimento das empresas, deixaram de fora a contração e declínio organizacionais. Sua perspicaz noção de autoperpetuação foi pouco desenvolvida, precisando de mais elaboração. 
A autoperpetuação organizacional está associada à capacidade da organização de sobreviver a seus membros. Uma noção relacionada é o conceito de institucionalização de Selznick (1957). Segundo este autor, "à medida que uma organização adquire um eu, uma identidade própria, ela se torna uma instituição. Dali para frente, a automanutenção torna-se mais do que mera sobrevivência organizacional” (Selznick, 1957, p. 21). Definindo a integridade institucional como "a persistência dos valores, competência e papel próprios de uma organização”, Selznick (1957, p. 119) sustenta que a integridade pode ser ameaçada externa e internamente pelo oportunismo e pela utopia, respectivamente. É atribuição da alta direção evitar ambos. Definindo o oportunismo como a busca de vantagens imediatas, de curto prazo, Selznick (1957, p. 146) sugere que, ao aceitar as imposições de um "princípio da realidade”, o oportunismo entrega parte da organização a forças externas, "permitindo que exerçam influência mais ampla sobre as políticas da empresa". Como resultado, o oportunismo solapa a integridade institucional. A utopia, por outro lado, "espera poder evitar escolhas difíceis fugindo para abstrações" (Selznick, 1957, p. 147). Ela também prejudica a integridade organizacional. Em particular, a utopia torna-se vítima do oportunismo, quando associada ao aventureirismo, isto é, a disposição a comprometer a organização como um todo, com base na avaliação parcial da situação. Em sua visão, a autopreservação de uma instituição vai além da sobrevivência. Ela requer a preservação da integridade organizacional. Em outras palavras, o desenvolvimento e a preservação da integridade organizacional são necessários para cultivar a propensão à autoperpetuação da organização.

\section{Síntese dos Aspectos Organizacionais e de Negócios no Sucesso e Fracasso de Longo Prazo}

A empresa moderna possui capacidade autoperpetuante. Longe de ser automática, essa capacidade potencial requer desenvolvimento. A capacidade de cultivar a propensão autoperpetuante seria indicador do sucesso de longo prazo da organização. A incapacidade de cultivar tal propensão reduz as chances de existência continuada da organização e, além disso, aumenta suas chances de autodestruição.

Os argumentos apresentados na seções anteriores foram organizados em um esquema de requisitos para o cultivo da propensão à autoperpetuação (vide Figura 2). 


\section{Figura 2: Desenvolvimento da Propensão à Autoperpetuação Organizacional}

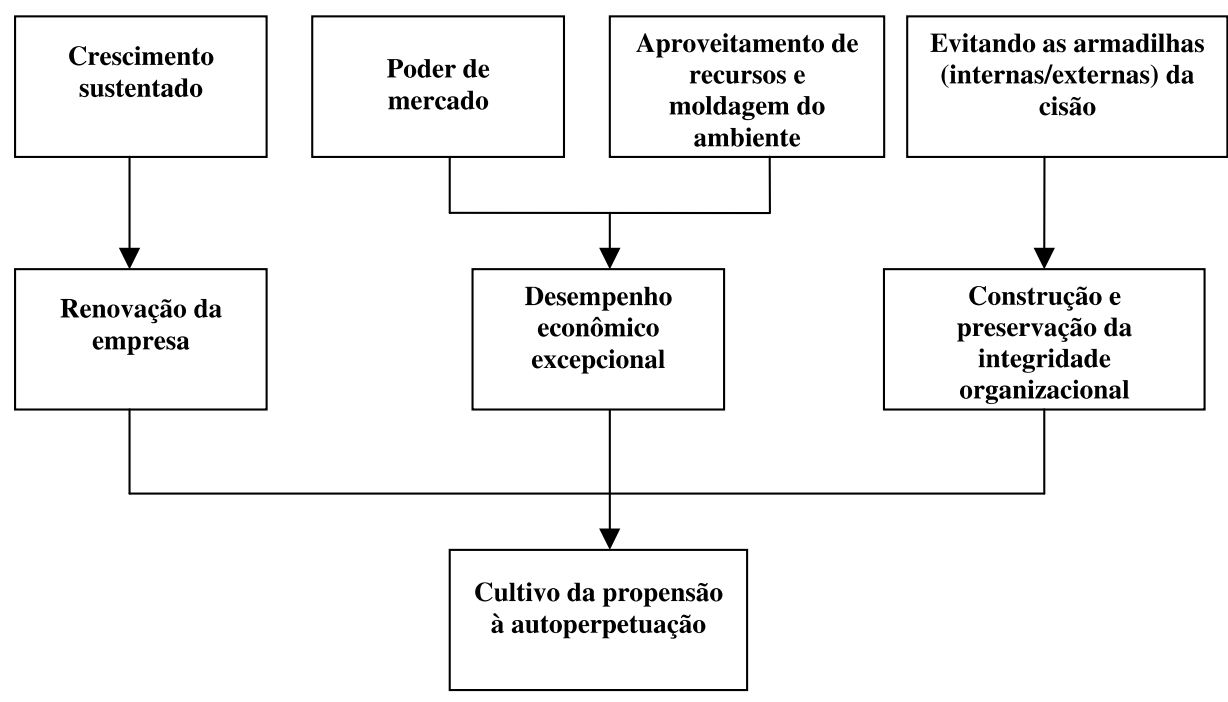

\section{Método de Pesquisa}

Realizou-se análise comparativa das histórias da GE e da WH do final da década de 1870 ao final da década de 1990. Tal desenho permite responder às perguntas como e por que (Yin, 1989), aumentar a visibilidade dos contrastes (Kieser, 1994), desenvolver teoria que generaliza as descobertas em proposições teóricas (Yin, 1989) e aguçar a visão do presente, sugerindo elementos teóricos transhistóricos (Lawrence, 1984).

Como já mencionado, o estudo utilizou um indicador de tamanho que permite visualizar a trajetória de crescimento da empresa ao longo da sua existência. Em essência, ele fornece uma descrição concisa do percurso da empresa na economia, permitindo comparar as trajetórias de crescimento da GE e da WH (vide Figura 1). O indicador expressa, de forma aproximada, a participação da empresa na economia em certo ponto do tempo. Essa qualidade serve bem ao estudo dessas duas empresas que se diversificaram amplamente. Um indicador mais preciso da participação da empresa na economia poderia ser obtido substituindo vendas por valor adicionado (vendas menos custo dos materiais). Porém isto se mostrou impraticável neste estudo, pela indisponibilidade de tais informações ao longo de doze décadas. 
O estudo empregou vários tipos de dados secundários, que forneceram informações históricas sobre as duas empresas, a constituição e desenvolvimento de certos setores de que elas participaram e acontecimentos no ambiente. Dois livros de bibliografias de negócios (Daniells, 1957; Geahigan, 1988), resenhas de artigos e livros em revistas de história dos negócios e resumos de teses contribuíram para a identificação de materiais escritos sobre as duas empresas. Outras fontes de informação regular foram o manual setorial da Moody's (19231997), a revista Fortune (1930-1999), a Business Week (1930-1947), os relatórios anuais das empresas (1971-1999) e as Estatísticas Históricas Internacionais de Mitchell (1998), que forneceram dados sobre o PNB norte-americano. Foi feito esforço para avaliar e conferir as fontes de informações, visando à confiabilidade (Gottschalk, 1950; Yin, 1989) e consistência (Goodman e Kruger, 1988). Por exemplo, os relatórios anuais e da Moody’s forneceram informações financeiras e organizacionais, como vendas, lucro líquido e número de funcionários. Esses dados foram usados para calcular indicadores e traçar as trajetórias das duas empresas na economia norte-americana. Os indicadores derivados exigiam o uso dos dados reais de cada ano. Como resultado, tomou-se cuidado especial para identificar e desconsiderar receitas ajustadas em função de aquisições e vendas de ativos.

Fatos históricos foram identificados e organizados de várias maneiras: (1) lista de eventos, associando para cada ano dois tipos de eventos, aqueles que ocorreram dentro e aqueles em torno da indústria elétrica norte-americana; (2) lista de eventos, classificando-os em diferentes setores da economia; (3) resumo da Moody's de cada empresa de 1922 a 1995, compreendendo diferentes tipos de informações financeiras, comerciais, operacionais, relacionadas à mão-de-obra, legislativas e organizacionais.

A análise avançou em várias direções. Mapas visuais (Langley, 1999), que comparam as duas empresas através do tempo, foram desenvolvidos. A estratégia de periodização (Langley, 1999) contribuiu para a compreensão da evolução das empresas e do setor através do tempo. De fato, o exame visual das curvas das trajetórias de crescimento da GE e da WH (vide Figura 1) revelou que o padrão sincrônico descrito pelas duas curvas até o final da década de 1950 mudou: no início, as empresas cresceram e se contraíram em sincronismo, o que deixou de ocorrer dali em diante. Além disso, a leitura do material coletado sugeriu uma série de temas dignos de investigação, tendo sido organizada uma lista comparativa GE x WH em vários temas. Quanto ao desenvolvimento de teoria, visando a revelar mecanismos explicativos (Kiser e Hechter, 1991; Bunge, 1996) para os padrões empíricos (Mintzberg e Waters, 1982), os padrões observados foram examinados à luz do esquema de requisitos para o cultivo da propensão à autoperpetuação organizacional (vide Figura 2). 


\section{Períodos na História da Indústria Elétrica Norte-Americana}

Um exame atento das trajetórias da GE e da WH (vide Figura 1) mostrou que o final da década de 1950 demarca dois períodos distintos: um período de notável sincronia até o final da década de 1950 e outro de trajetórias divergentes dali em diante. Além disso, a análise histórica dos primeiros anos de suas existências revelou mudanças substanciais no início da década de 1910, como a concessão à GE da patente do filamento dúctil de tungstênio, o afastamento de George Westinghouse da WH, empresa que ele fundara em 1886, e a ação antitruste contra a GE, WH e outras 37 empresas do setor. Como resultado, o estudo distingue três grandes períodos no setor: formação (1880-1910), período estruturado (1910-final dos anos 1950) e reestruturação (dali em diante).

\section{Período de Formação (1880-1910)}

Quando a GE se constituiu em pessoa jurídica, em 1892, o setor elétrico abrangia a iluminação (arco voltaico a carvão e lâmpadas incandescentes), energia (motores elétricos de corrente contínua) e tração elétrica (carris elétricos e trens elevados). Àquela altura, as três maiores empresas do setor elétrico eram a Edison General Electric (EGE), fundada por Thomas Edison em 1878; Thomson-Houston (TH), fundada por um grupo de investidores e os inventores Elihu Thomson e E. Houston em 1883; e Westinghouse, fundada por George Westinghouse em 1886. A fusão da EGE e T-H em 1892 deu origem à GE, e um duopólio - GE \& WH - estabeleceu-se em várias linhas de equipamentos no setor elétrico. Com o tempo, somente estas duas empresas viriam a desenvolver uma linha completa de produtos no que se tornou um setor oligopolista.

Tendo reduzido o número de protagonistas do setor, a fusão da EGE e T-H na GE, em abril de 1892, contribuiu para reduzir a intensidade da concorrência no setor. Àquela altura, a velocidade da mudança tecnológica no setor começara a declinar, com a fixação de padrões. Na recém-formada GE, a equipe de alta administração incluía ex-executivos das duas empresas, embora a grande maioria viesse da $\mathrm{T}-\mathrm{H}$, tendo o antigo presidente da $\mathrm{T}-\mathrm{H}$, Charles Coffin, se tornado o primeiro presidente da GE. Concluída a fusão, o setor passou a ter duas grandes empresas, em vez de três, sendo uma (GE) várias vezes maior do que a outra (WH).

Logo após a sua fundação, a GE enfrentou o Pânico Financeiro de 1893. Dali para frente, até 1898, a indústria elétrica enfrentou condições adversas. Além da drástica redução das vendas e dos lucros, os títulos de empresas-clientes detidos pela EGE e T-H se desvalorizaram. Foi preciso dar baixa em ativos da GE, que 
caíram de US\$50 milhões, em 1893, para US\$27 milhões em 1900. Diante de tais condições precárias, a GE foi forçada a adotar uma política financeira conservadora. A empresa subseqüentemente usou as condições econômicas adversas de meados da década de 1890 para impor condições aos seus concorrentes em decadência. Em 1900, a GE inaugurou seu laboratório de pesquisas (RLAB), a fim de enfrentar a ameaça de obsolescência tecnológica. Conquanto seu principal propósito fosse o domínio da GE em lâmpadas, o RLAB também deveria descobrir novos campos rentáveis para a GE explorar.

Durante a década de 1890, enquanto a GE se recuperava do Pânico Financeiro de 1893 e conquistava posição dominante nas bem-estabelecidas linhas de negócios do setor, a WH se expandia no exterior. O desenvolvimento da WH diferira daqueles da EGE e da T-H. Essas duas empresas, em grande medida, haviam financiado estações centrais, aceitando títulos de empresas-clientes como pagamento parcial pelos equipamentos vendidos. A WH, por sua vez, preferira receber dinheiro. Como resultado, o Pânico Financeiro de 1893 mal a afetou.

Na depressão econômica de 1907-1908, porém, chegou a vez de a WH enfrentar graves problemas financeiros. Tendo expandido seu império internacional exagerada e rapidamente, o confiante George Westinghouse havia corrido riscos demais para implementar sua visão. O império diversificado que construíra ao redor do mundo havia sido, em grande parte, financiado por seu próprio dinheiro, havendo apenas número reduzido de investidores com participações minoritárias. Nenhum grupo poderoso de banqueiros vinha protegendo as empresas dele, pois evitara sistematicamente trazer financistas para suas empresas, por não desejar ceder seu controle para ninguém. A depressão de 1907 deixou a WH em maus lençóis, exigindo a intervenção de financistas. Embora mantido na presidência, George Westinghouse perdeu seu poder na empresa e afastou-se totalmente em 1911. A coordenação interna das várias peças do enorme sistema empresarial e organizacional concebido por ele estava em grande parte concentrada em sua mente poderosa. A remoção de George Westinghouse do poder deixou a empresa mal articulada dali para frente.

\section{Período Estruturado (de 1910 ao final dos anos 1950)}

Como mostra a Figura 1, durante esse período, a GE e a WH seguiram trajetórias sincronizadas. Dois aspectos principais caracterizam esse período. Primeiro, a estrutura do setor estabilizou-se. Segundo, o chamado círculo benigno da energia inspirou a diversificação das empresas, de modo que duas classes de produtos - eletrodomésticos e aparatos - contribuíam para seu crescimento mútuo. Durante esse período, as duas companhias elétricas integradas desenvolveram suas carteiras de negócios de formas bem semelhantes, sendo rivais em 
praticamente todas as linhas de negócios, com exceção de estações de rádio, elevadores e escadas rolantes, negócios de que apenas a WH tomou parte.

A estrutura da indústria elétrica norte-americana evoluiu para uma estrutura guarda-chuva. Ao coordenar os protagonistas do setor, promover ativamente a inovação e neutralizar fontes externas de mudança, a GE sistematicamente forjou um manto protetor para as empresas industriais elétricas, proporcionando generosos retornos aos protagonistas. A GE desempenhou o papel central e reservou uma posição privilegiada para a WH, enquanto a maioria dos outros protagonistas orbitava em torno dessas duas empresas. Durante esse período, os segmentos de negócios mais importantes foram as lâmpadas, aparatos e eletrodomésticos. Embora os lucros das lâmpadas fossem proporcionalmente os maiores e mais regulares do setor, os aparatos representavam o grosso das vendas, que dependiam fortemente do estado da economia, e eletrodomésticos eram o segmento mais promissor.

A formação da estrutura guarda-chuva começou bem cedo. Para auferir os benefícios potenciais das patentes da lâmpada de Edison, a GE iniciou uma série de ações de coordenação no setor: acordos com fornecedores em 1895 (bulbos de vidro, maquinário de fabricação das lâmpadas), acordos de licenciamento mútuo de patentes com a WH (1896), acordos de compartilhamento de mercados (1896), organização da Associação de Fabricantes de Lâmpadas Incandescentes (AFLI) em 1896 e financiamento de rivais (1901). A AFLI fixava preços e volumes de produção com base nos preços e volumes de vendas da GE. O financiamento pela GE de fabricantes independentes de lâmpadas dava-se por meio de uma holding (National), da qual a GE detinha 75\%. A estratégia do negócio de lâmpadas da GE tinha dois grandes objetivos: maximizar as margens e evitar a concorrência por preços.

A maximização das margens requer aumento na percepção do valor e redução nos custos de fabricação. Inovações nos produtos (lâmpadas GEM, de tungstênio e Mazda) e nos processos (fabricação de lâmpadas) desenvolvidos no laboratório de pesquisas da GE permitiram à empresa alcançar os dois objetivos. O trabalho de pesquisa aumentou a qualidade das lâmpadas existentes, além de inventar novas lâmpadas para novos usos, contribuindo para sustentar ou mesmo aumentar os níveis do valor percebido. Os processos industriais também foram melhorados pelo laboratório, permitindo à GE a redução de custos.

Para neutralizar fontes potenciais de pressão para a queda dos preços que pudessem desencadear uma guerra de preços, a GE procurava manter sob controle os volumes produzidos e os preços dos produtos do setor. Seus licenciados recebiam quotas de produção relativas à própria produção da GE. Como resultado, 
o setor inteiro podia aumentar ou eventualmente reduzir harmoniosamente a produção, evitando a formação de estoques indesejados e pressões sobre os preços. Além disso, por meio de suas práticas comerciais, que evoluíram da fixação dos preços no varejo a esquemas de consignação, a GE fixava os preços.

Por sua própria natureza, a mudança causal era provocada por fatores externos (econômicos, políticos, sociais etc.), permanecendo, portanto, fora de controle. Sob condições externas favoráveis, o setor inteiro crescia sincronicamente, enquanto eventuais condições desfavoráveis resultavam em contração. A fabricação de lâmpadas, portanto, assemelhava-se ao que Porter (1988) denomina um setor cinco estrelas, cujos retornos são maximizados graças à neutralização das pressões que possam prejudicar a sua rentabilidade. Fornecedores e compradores eram neutralizados por meio de acordos e esquemas de consignação; novos protagonistas eram neutralizados pelo recurso a ações legais, legislação governamental ou novos produtos especialmente projetados para concorrer com produtos estrangeiros; a rivalidade era neutralizada pela aquisição de empresas menores pela GE e pela $\mathrm{WH}$, bem como pelo controle de preços e do volume de produção. Ela própria uma tecnologia substituta da iluminação a gás, a iluminação elétrica não enfrentou a pressão de produtos substitutos.

As iniciativas da GE trouxeram estabilidade e lucros para todos os protagonistas do setor, embora os lucros fossem desigualmente distribuídos. A GE detinha a maior participação no mercado, lançava constantemente produtos novos e melhores e vivia aperfeiçoando seu processo de fabricação. Como resultado, suas margens e lucro total eram bem maiores do que aqueles dos concorrentes. A WH tinha a segunda maior participação no mercado e se associou à GE em várias áreas, como novos produtos (lâmpadas Mazda, por exemplo), atividades de exportação e educação do público norte-americano sobre as virtudes dos eletrodomésticos. Com o tempo, a WH negociou aumentos de sua quota de produção e reduções no pagamento de royalties à GE. A WH, portanto, ocupou um privilegiado segundo lugar em lâmpadas.

A estrutura do setor de aparatos elétricos também assumiu uma forma de guardachuva. O licenciamento mútuo entre a GE e a WH e a natureza complexa dos produtos fabricados sob encomenda contribuíram para limitar o número de fabricantes integrados no setor. De fato, a GE e a WH dominaram o segmento de aparatos, com as duas maiores participações no mercado, enquanto enfrentavam uma série de rivais especializados menores, como a Allis-Chalmers. A relação que a GE mantinha com empresas industriais elétricas estrangeiras protegia o mercado norte-americano de concorrentes estrangeiros.

O controle de preços foi estimulado em várias ocasiões. Em 1926, as empresas 
do setor organizaram-se em torno da National Electrical Manufacturers' Association (NEMA), que resultou da fusão de três associações de classe. A NEMA visava a cooperar com o Departamento de Comércio norte-americano na padronização e simplificação. Suas reuniões promoveram a cooperação entre os concorrentes, a fim de estabelecer, entre outras coisas, um sistema contábil uniforme. Os protagonistas do setor esperavam que esses esforços resultassem em preços uniformes. Durante a Grande Depressão, a Lei da Recuperação Industrial Nacional desencorajou a concorrência de preços, devido ao tremendo colapso dos pedidos de equipamentos elétricos na década de 1930, quando as vendas caíram de US\$81 milhões para US\$16 milhões. O governo norteamericano restabeleceu o controle de preços durante a Segunda Guerra Mundial. Depois da guerra, encontros secretos informais para fixar preços, organizar lances e estabelecer parcelas de participação de mercado contribuíram para reduzir a concorrência baseada em preços e estimular a estabilidade de tais parcelas.

Além disso, as concessionárias de energia não estavam qualificadas para fabricar seus próprios aparatos numa integração para trás. A sua dependência dos fabricantes de aparatos era enorme. Para contrabalançar o poder dos fabricantes, especialmente o duopólio GE-WH, essas empresas estimulavam a concorrência entre os fabricantes e, quando possível, distribuiam um pedido entre as empresas concorrentes. De maneira curiosa, era do interesse da maioria dos protagonistas - concessionárias, governo (como cliente e regulamentador) e empresas (GE e WH) - que tanto a GE como a WH estivessem em boa forma.

O círculo benigno de energia, conceito formulado pelo presidente da GE, Gerald Swope, inspirou a diversificação para os eletrodomésticos. Contudo o segmento dos eletrodomésticos não se desenvolveu numa estrutura de guarda-chuva. $\mathrm{O}$ primeiro eletrodoméstico produzido em massa, o rádio, cujo lançamento no mercado teve ainda mais sucesso do que as lâmpadas, não recompensou os proprietários das patentes, tanto quanto as lâmpadas. Dois fatores principais parecem explicar a incapacidade dos pioneiros de auferir os benefícios de suas patentes: falta de visão e baixa complexidade tecnológica. Ao contrário das lâmpadas, cujo mercado já existia e, ao que se esperava, deveria continuar crescendo por longo tempo, o rádio foi um produto totalmente novo, para o qual não havia sido desenvolvida nenhuma infra-estrutura - estações transmissoras. Diante dessa situação, as empresas pioneiras - GE, WH e a joint-venture delas com a AT\&T, a RCA — esperavam apenas um baixo volume de vendas para fins militares. Como resultado, o preço do produto inicialmente fixado foi alto, e as licenças emitidas não estipularam nenhum tipo de restrição ao volume de produção. Ao contrário dos aparatos, o rádio não envolvia tecnologia de fabricação complexa, facilitando a imitação, o que aconteceu quando o mercado explodiu, demandando um produto cujo preço prometia retornos generosos, se produzido 
em massa. Em suma, os pioneiros não conseguiram sustentar por muito tempo a vantagem competitiva inicial. De forma semelhante, outros eletrodomésticos, como o refrigerador Top Monitor da GE, não recompensaram por muito tempo seus inventores, já que a rivalidade no setor foi intensa. Como os eletrodomésticos representavam apenas uma pequena parte da indústria elétrica, a estrutura guardachuva em lâmpadas e aparatos forneceu um manto protetor à maioria dos fabricantes, permitindo que crescessem em sincronia com o estado geral da economia.

Finalmente, ao implementar essa estratégia guarda-chuva, a GE simultaneamente ergueu defesas para todo o setor e experimentou expansão produtiva, ou seja, uma expansão que estimulou um uso mais produtivo de seus recursos. Em suma, a GE adotou o que podemos chamar de abordagem híbrida (produtiva e defensiva) de expansão - expansão que aumenta a produtividade enquanto protege as linhas de negócios existentes.

\section{Período de Reestruturação (final da década de 1950 em diante)}

No final da década de 1950, a estrutura guarda-chuva, cuidadosamente erguida, estava sendo demolida. O setor elétrico estava sob estreito escrutínio do Departamento de Justiça norte-americano. A GE, a WH e 27 outras empresas do setor enfrentaram os tribunais. Um total de 45 executivos do setor foram acusados de conluio para fixar preços, manipular lances e dividir mercados. O escândalo do conluio revelou a última tentativa desesperada dos participantes do setor de jogar dentro das velhas regras. Dali em diante, a concorrência incluiria, entre suas variáveis, o preço e novos protagonistas lutando por fatias do mercado. Além disso, a GE e a WH enfrentavam o desafio de gerir organizações cada vez maiores, de negociar com sindicatos cada vez mais organizados e exigentes, e de se aventurar em numerosos novos mercados e linhas de negócios. Um novo jogo estava prestes a iniciar.

Duas razões subjacentes parecem ajudar a explicar por que e como a GE e a WH acabaram seguindo duas trajetórias bem diferentes após tantos anos de sincronia. Embora tanto a GE como a WH estivessem despreparadas para enfrentar as numerosas mudanças ambientais que fizeram desmoronar o guardachuva, a WH acabou adotando uma abordagem de construção de império, que não protegeu os negócios existentes nem aumentou sua produtividade. Além disso, a WH foi menos diligente em relação à gestão do risco.

Com o desmoronamento do guarda-chuva, aumentou muito a incerteza. Grande parte das táticas da GE de neutralização da mudança foram interrompidas ou se tornaram infrutíferas. Os acordos de licenças, que especificavam quotas de 
produção, não foram renovados, inibindo a coordenação pela GE do volume de produção no setor. O licenciamento mútuo de patentes deixou de ser praticado. Além disso, rivais menores, como a Sylvania, passaram a realizar pesquisas próprias. Ficou mais difícil justificar um aumento nas tarifas de importação para impedir a entrada de empresas estrangeiras, que começaram a fabricar equipamentos nos Estados Unidos. As concessionárias de energia e os sindicatos começaram a pôr em ação seu poder de barganha. Finalmente, o conhecimento científico e tecnológico havia-se espalhado pelo mundo. Como resultado, tornouse cada vez mais difícil neutralizar a ameaça de ser ultrapassado por novidades tecnológicas. Em suma, o setor cinco estrelas gradualmente perdeu suas estrelas e viu seus polpudos retornos se reduzirem drasticamente.

Em muitos aspectos, as duas empresas reagiram às novas circunstâncias da mesma maneira. Como resultado, elas ocasionalmente cometeram erros semelhantes, por vezes enormes. Para enfrentar essa reestruturação ambiental, ambas se protegeram das oscilações econômicas, formando carteiras diversificadas de negócios. Seus primeiros passos rumo à diversificação foram semelhantes: eletrodomésticos, novos campos de alta tecnologia, indústria bélica. Ambas tiveram êxito em alguns empreendimentos, como o radar (WH) e turbinas de aviões (GE), e fracassaram em outros, como a dessalinização da água (WH) e computadores (GE). Ambas também ingressaram em vários novos empreendimentos menores, embora não-lucrativos. Ambas desenvolveram ainda mais seus negócios bélicos, que passaram a representar partes substanciais de suas vendas anuais, mas acabaram enfrentando um desaquecimento devido à redução dos orçamentos governamentais. Ambas ocuparam posições proeminentes no recém-nascido campo nuclear, que no entanto não se tornou o empreendimento rentável e de alto crescimento como se esperava. Ambas perderam terreno nos campos em que haviam sido pioneiras, como a eletrônica. Além disso, ambas sofriam alternadamente dos problemas de falta de capacidade para atender à demanda, ou super-estocagem, indicando que estavam despreparadas para gerir a produção pós-guarda-chuva. Finalmente, ambas as subsidiárias financeiras alcançaram crescimento e desempenho excepcionais nos anos 1980, tendo porém enfrentado enormes escândalos nos anos 1990.

A despeito das semelhanças, as duas empresas também diferiam de várias maneiras. Em primeiro lugar, enquanto as principais iniciativas da GE, fora do campo bélico, eram em alta tecnologia, as principais iniciativas da WH foram em áreas de baixa tecnologia. Enquanto a GE ingressou nos ramos de computadores, turbinas de aviões e plásticos, a WH ingressou no aluguel de carros, construção civil, vendas por catálogo, casas de baixo custo, motéis, engarrafamento de refrigerantes, pousadas e relógios suíços. Além disso, a abordagem de expansão assistemática da WH voltou-se tipicamente para a 
construção de um império, ou seja, a seleção das aquisições não era determinada por motivações produtivas ou defensivas. O crescimento da WH visou na maior parte objetivos financeiros, e não estratégicos. Por outro lado, ao enfatizar empreendimentos de alta tecnologia, com freqüência a GE crescia em direções em que podia fazer uso mais produtivo de seus recursos e habilidades tecnológicas existentes, ou seja, em campos onde poderia ter inicialmente alguma vantagem competitiva.

Outra diferença importante entre as duas empresas envolvia suas abordagens em relação ao risco. Enquanto a WH freqüentemente se expunha ao risco, a GE costumava se proteger dele. A desatenção ao risco levou a WH a assumir compromissos caros em campos tão variados como construção civil, vendas por catálogo e energia nuclear. A atenção ao risco impediu a GE de assumir compromissos desnecessários em campos como energia nuclear, e permitiu que se retirasse em tempo de campos não-lucrativos, como o ramo dos computadores. Os prejuízos da WH eram proporcionalmente bem maiores do que os da GE. Como resultado, a má gestão do risco erodiu a riqueza da WH e consumiu tempo gerencial, que poderia ter sido alocado para estimular o crescimento produtivo. Como mostra a Figura 1, de meados da década de 1970 em diante, a WH sofreu constante processo de contração.

\section{Traços Distintivos da Ge e da Wh}

O desenvolvimento organizacional da GE e da WH diferiu consideravelmente entre si ao longo de suas existências. É possível identificar os traços distintivos que cada empresa desenvolveu nos anos de formação. Os traços de cada empresa, além de orientarem as suas principais políticas ao longo de suas existências, também contribuíram para determinar seus destinos. Esta seção apresenta primeiro os traços das empresas, para depois discuti-los em relação ao cultivo de propensão organizacional à autoperpetuação.

\section{Os Traços}

Três traços orientados aos negócios foram identificados. Em primeiro lugar, as empresas diferiam no espírito empreendedor. Como mostrou Penrose (1980), na ausência de ambição uma empresa não cresce, e a gestão descuidada do risco no crescimento compromete a firma. Enquanto a GE perseguia sistematicamente objetivos ambiciosos, correndo riscos compatíveis, a WH corria riscos exagerados em prol de objetivos satisfatórios. 
A GE e a WH diferiam em dois outros aspectos: os motivos do crescimento e a abordagem da mudança. A GE apoiava-se em grande parte em motivos produtivos e híbridos (simultaneamente produtivos e defensivos), embora esporadicamente efetuasse expansão meramente defensiva. A WH também perseguia motivos produtivos mas apoiava-se em alto grau em motivos meramente defensivos, ou mesmo nem produtivos nem defensivos. Quanto à abordagem da mudança, a GE procurava lidar ativamente, sempre que possível, com todo o tipo de mudança dentro e fora dela. Já a WH tendia a aceitar passivamente a mudança.

Quatro traços organizacionais foram identificados. À medida que uma empresa cresce, aumenta a diversidade. Ao enfatizar as semelhanças dentro da diversidade, a GE se esforçava sistematicamente pela integração das suas partes. A WH tendia a enfatizar diferenças, causando a sua fragmentação em partes quase autônomas. A GE e a WH diferiam em três outros aspectos: ao abordar os conflitos de prioridades, a complexidade e a necessidade de talentos gerenciais.

À medida que a empresa cresce, aumentam os conflitos de prioridades. A GE enfrentava os conflitos de prioridade com processos de coordenação fortes e deliberados. Já as fracas habilidades de coordenação da WH produziam um processo pouco estruturado.

À medida que a empresa cresce, aumenta a complexidade: as questões administrativas são cada vez mais difíceis de entender. Na GE, a solução de problemas era conduzida de forma sistemática, com a identificação detalhada, e geralmente demorada, das informações pertinentes. A WH abordava a solução de problemas gerenciais de forma assistemática, ou seja, aplicando soluções rápidas, geralmente do tipo ‘apaga-incêndio’.

À medida que a empresa cresce, aumenta a necessidade de talentos gerenciais. Os serviços gerenciais são o mais importante fator limitador do crescimento da empresa (Penrose, 1980). Além disso, as empresas precisam desenvolver continuamente seu pessoal, para evitar problemas de sucessão em todos os níveis da hierarquia. A GE tem consistentemente desenvolvido ampla base de talentos gerenciais. As ações da WH nessa área foram reativas e não proativas. Alguns exemplos ilustram os traços de cada empresa (vide Quadro 1). 


\section{Quadro 1: Evidências dos Traços da GE e da WH}

\begin{tabular}{|c|c|c|}
\hline & Traços da General Electric & \begin{tabular}{|l|} 
Traços da Westinghouse \\
\end{tabular} \\
\hline \multicolumn{3}{|l|}{ De negócios } \\
\hline $\begin{array}{l}\text { Espírito } \\
\text { empreendedor }\end{array}$ & $\begin{array}{l}\text { Objetivos ambiciosos e riscos compatíveis } \\
\text {. Fusão buscando a dominância no setor } \\
\text {. Expansão maximizada na } 2^{a} \text { Guerra } \\
\text {. Retenção de negócios onde for \#1 ou \#2 } \\
\text {. Proteção contra riscos (energia nuclear) e } \\
\text { evitando riscos desnecessários (produção } \\
\text { artificial de chuva) }\end{array}$ & $\begin{array}{l}\text { Objetivos satisfatórios e riscos } \\
\text { exagerados } \\
\text {. A número } 2 \text { no setor } \\
\text {. Expansão propositadamente moderada } \\
\text { a } 2^{\mathrm{a}} \text { Guerra } \\
\text {. Expansão arriscada antes da } 1^{\mathrm{a}} \text { e após a } \\
2^{\mathrm{a}} \text { Guerra }\end{array}$ \\
\hline $\begin{array}{l}\text { Motivos da } \\
\text { expansão }\end{array}$ & $\begin{array}{l}\text { Produtivos, defensivos, ambos } \\
\text {. Fusão buscou eficiência e defesa } \\
\text {. Aquisições da GE Capital (ambos) } \\
\end{array}$ & $\begin{array}{l}\text { Produtivos, defensivos, nenhum deles } \\
\text {. Expansão inicial no exterior (nenhum) } \\
\text {. Expansão após a } 2^{\mathrm{a}} \text { Guerra (nenhum) } \\
\end{array}$ \\
\hline $\begin{array}{l}\text { Visão de mundo } \\
\text { da mudança }\end{array}$ & $\begin{array}{l}\text { Tratamento ativo da mudança } \\
\text { Moldagem do ambiente } \\
\text {. Construção da estrutura guarda-chuva } \\
\text {. Neutralização de sindicatos por duas décadas }\end{array}$ & $\begin{array}{l}\text { Adaptação passiva à mudança } \\
\text { Aceitação do ambiente } \\
\text {. Seguidora da liderança da GE } \\
\text {. Seguidora das receitas do setor (best } \\
\text { practices e diversificação) }\end{array}$ \\
\hline \multicolumn{3}{|l|}{ Organizacionais } \\
\hline Diversidade & $\begin{array}{l}\text { Integração (visando economias de escala e } \\
\text { escopo) } \\
\text {. Desafio inicial: a fusão } \\
\text {. A noção de 'família GE' } \\
\text {. Aplicação do monograma da GE em todos os } \\
\text { produtos } \\
\text { Mecanismos de comunicação e trocas entre } \\
\text { unidades da firma }\end{array}$ & $\begin{array}{l}\text { Fragmentação (ênfase na autonomia) } \\
\text {. GW adicionou unidades industriais } \\
\text { quase autônomas } \\
\text {. Afastamento de GW e sua substituição } \\
\text { por um financista (alta direção } \\
\text { dissociada do restante da empresa) } \\
\text {. Dissociação da fabricação e marketing } \\
\text {. Formação do conglomerado não- } \\
\text { integrado }\end{array}$ \\
\hline $\begin{array}{l}\text { Conflitos das } \\
\text { prioridades }\end{array}$ & $\begin{array}{l}\text { Coordenação forte } \\
\text {. Envolvimento da alta direção } \\
\text {. Ampla utilização de comitês }\end{array}$ & $\begin{array}{l}\text { Coordenação fraca } \\
\text {. Alta direção tímida e hesitante } \\
\text {. Diversificação descoordenada }\end{array}$ \\
\hline Complexidade & $\begin{array}{l}\text { Soluções sistemáticas para questões } \\
\text { gerenciais } \\
\text {. Visão geral ampla, coleta de informações, } \\
\text { análise detalhada e quantificação } \\
\text {. Invenção de indicadores e medidas } \\
\text {. Neutralização da pressão sindical } \\
\text {. Processo de descentralização } \\
\text {. Prevenção/detecção de problemas cedo } \\
\end{array}$ & $\begin{array}{l}\text { Soluções assistemáticas para questões } \\
\text { gerenciais } \\
\text {. Quantificação e controle irregulares } \\
\text {. Tentativas efêmeras e esporádicas } \\
\text { (Vabastram) } \\
\text {. Problemas atingindo altas proporções e } \\
\text { sendo enfrentados mediante soluções } \\
\text { casuísticas }\end{array}$ \\
\hline $\begin{array}{l}\text { Necessidades de } \\
\text { talentos gerenciais }\end{array}$ & $\begin{array}{l}\text { Esforços consistentes de desenvolvimento } \\
\text { Pioneira em programas de treinamento para } \\
\text { trabalhadores qualificados e engenheiros } \\
\text {. Preocupação desde cedo com avaliação, } \\
\text { promoção e sucessão } \\
\text {. Treinamento e doutrinação gerenciais }\end{array}$ & $\begin{array}{l}\text { Esforços inconsistentes de } \\
\text { desenvolvimento } \\
\text {. Imitou os programas de treinamento } \\
\text { para trabalhadores qualificados e } \\
\text { engenheiros anos depois } \\
\text {. Persistente problema de sucessão } \\
\text { (desde a substituição de GW) } \\
\text { Tentativas mal-estruturadas de treinar } \\
\text { gerentes }\end{array}$ \\
\hline
\end{tabular}

\section{Os Traços das Empresas e o Cultivo da Propensão Organizacionalà Autoperpetuação}

Esta seção apóia-se nos fundamentos teóricos apresentados para sustentar que o conjunto de traços desenvolvido desde cedo por cada empresa determinou 
seus destinos. Os traços da GE alimentaram sistematicamente sua propensão à autoperpetuação. Já a WH fomentou uma propensão à autodestruição, mantida oculta por várias décadas sob o guarda-chuva protetor construído pela GE. Os traços da GE cultivaram os três requisitos de primeiro nível, isto é, renovação, desempenho e integridade (vide Figura 2), enquanto os da WH estimularam apenas o requisito da renovação organizacional.

\section{Renovação Organizacional}

Pesquisa e Desenvolvimento (P\&D) nas duas empresas contribuiu com invenções e inovações tecnológicas que produziram a renovação organizacional por meio de processos de crescimento sustentado mediante diversificação relacionada. O reconhecimento de sua perícia e paridade tecnológicas estava tão profundamente arraigado no setor que, no final da década de 1980, Jack Welch ainda temia a WH. A base tecnológica da WH, porém, havia-se enfraquecido progressivamente. Com o agravamento dos problemas financeiros da empresa, a sua capacidade de alocar recursos para P\&D reduziu-se bastante.

Dois traços podem ser associados à renovação organizacional: os motivos da expansão e o espírito empreendedor. Os traços da GE estimularam sistematicamente o crescimento sustentado. Seus objetivos ambiciosos de crescimento e dominância e sua cautela em relação aos riscos estimulariam novos empreendimentos relacionados, desde que sujeitos a níveis de risco razoáveis. Sua preocupação com a produtividade, eficiência, economias de escala e escopo, e aquisição e manutenção do poder de mercado impediram que seguisse a trajetória da construção de império (expansão nem produtiva, nem defensiva).

Os objetivos de crescimento sistematicamente satisfatórios da WH, combinados com a sua atitude descuidada em relação ao risco, produziram surtos de expansão arriscada, seguidos de períodos de reparos para corrigir erros, uma indicação da pouca capacidade da empresa de estimular o crescimento sustentado. Ademais, a WH periodicamente se dirigia à construção de império, produzindo expansão que não renovava as atividades existentes.

\section{Desempenho Excepcional}

O desempenho da GE tem sido sistematicamente excepcional. Ela tem conseguido não apenas criar, capturar, explorar, preservar e reconfigurar numerosos recursos valiosos, mas também exercer poder de mercado em diversos domínios setoriais. De fato, das 12 linhas de negócios constantes do relatório anual de 1997, somente as estações de rádio e TV eram novidade para a GE. Todas as outras haviam iniciado no máximo em 1905. Desde cedo, sob a liderança 
de Charles Coffin, a GE começou a desenvolver capacitações dinâmicas no setor elétrico emergente e em rápida mudança. A luta por patentes valiosas, participação no mercado e lucros foi concomitante ao desenvolvimento de processos gerenciais e organizacionais, que têm sido regularmente melhorados ao longo da sua existência. Durante a construção da estrutura guarda-chuva, a GE valeu-se de seus valiosos ativos e processos não apenas para estabilizar as relações do setor, mas também para consolidar o seu poder de mercado. O desempenho da WH, por outro lado, não foi nada excepcional. Seus ativos valiosos valeram-lhe o segundo lugar no setor. Seus processos, porém, não promoveram o aprendizado, a integração dos recursos e a reconfiguração adequada. O sucesso inicial da WH no setor elétrico emergente esvaneceu-se, à medida que este começou a se estabilizar; dali em diante a WH seguiria a líder do setor, desempenhando papel secundário.

O traço visão de mundo sobre a mudança desempenha papel importante na gestão dinâmica dos recursos e na capacidade de exercer poder de mercado prolongado. Ao longo dos três períodos, a GE e a WH abordaram a mudança, dentro e em torno delas, de maneira bem diferente. A GE aplicou tratamento proativo à mudança, de forma a prever e melhor utilizar as oportunidades e ameaças que se formavam dentro e em torno dela. Tal tratamento compreendia a identificação de diferentes fontes de mudança interna e externa e rápidas ações, visando assegurar à GE a melhor posição possível em cenário mutável. Por meio de escrutínio sistemático da mudança, a GE procurou identificar com antecipação a mudança. Por exemplo, para antecipar a mudança tecnológica no recém-nascido setor elétrico, a GE não apenas criou seu Laboratório de Pesquisa, mas também manteve relações estreitas, via participação no capital social, com fábricas européias do setor. Ao implementar uma série de mecanismos - licenças, acordos, aquisições, joint-ventures e alianças - a GE procurava tirar o melhor proveito da mudança, a ponto de neutralizá-la, sempre que possível e aconselhável. A gestão do negócio de lâmpadas oferece claro exemplo da abrangência da abordagem da GE. A GE também procurou proteger da concorrência destrutiva os protagonistas do setor. Durante os dois primeiros períodos, a GE desempenhou importante papel coordenador, que foi interrompido, mas não totalmente eliminado, no terceiro período. Um bom exemplo são os estudos da inflação realizados por ela na década de 1970. Aqueles estudos visavam a compreender melhor os efeitos da inflação nos negócios e derivar estratégias de crescimento em ambiente de inflação alta. Os estudos mostraram que, em economia inflacionária, se os custos reais não fossem conhecidos, os preços seriam equivocadamente fixados baixos demais e os lucros se reduziriam. Acreditando que todas as empresas do setor se beneficiariam se conhecessem seus custos reais, a GE compartilhou suas descobertas por meio do programa de treinamento de executivos COIN (Effectively COping with INflation - Lidar Eficazmente 
com a Inflação). Ao compartilhar suas descobertas com outras grandes empresas, a GE estava reproduzindo seu comportamento estratégico como coordenador do setor. Em suma, a sua visão estratégica tem sistematicamente ultrapassado as suas próprias fronteiras.

A WH, por outro lado, tendia a aceitar passivamente a mudança. Confortavelmente colocada em posição privilegiada na estrutura guarda-chuva do setor, a WH desfrutava um estável segundo lugar. Sob a coordenação da GE, com exceção do desenvolvimento tecnológico, a WH tendia a reagir aos lances da GE pela imitação. Com isso, a WH deixou de desenvolver capacitações para exercer poder no mercado, bem como capacitações dinâmicas para enfrentar os ambientes mutáveis. Com a retirada da GE do papel de coordenador, a WH passou a reagir erraticamente à mudança e a exibir desempenho longe de excepcional.

\section{Integridade Organizacional}

Os quatro traços relacionados à organização podem ser associados à integridade organizacional. Em todos eles, os traços da GE contribuíram sistematicamente para preservar a integridade organizacional, enquanto os da WH colocaram sistematicamente em risco a sua integridade. Até o desmantelamento do guardachuva, a estrutura favorável do setor neutralizava a maioria das ameaças à integridade da WH.

Preservar a integridade da GE constituía preocupação permanente, em todos os níveis da organização. $\mathrm{Na} \mathrm{WH}$, a preservação da integridade não era preocupação importante. A rivalidade organizacional, conseqüência esperada da crescente diversidade, era neutralizada na GE por meio de mecanismos como a noção da 'família GE', a decisão de aplicar o seu monograma em todos os seus produtos ou a descentralização coordenada que efetuou no início da década de 1950. A fragmentação da WH em unidades e funções quase autônomas reforçaria a rivalidade organizacional.

Conflitos de prioridade, se não apropriadamente coordenados, também podem ameaçar a integridade de uma empresa. As duas empresas também diferiram neste aspecto. Enquanto a GE se valia amplamente de comitês e da alta administração para facilitar a coordenação e tratar dos conflitos, a tendência da WH era deixar as unidades lidarem por si próprias com os desacordos. Isto se explica em parte pela fragmentação da WH e pela autoridade limitada da alta administração sobre as partes da empresa. Por exemplo, pouco depois de irromper a Segunda Guerra Mundial na Europa, o governo norte-americano começou a solicitar que a indústria norte-americana cooperasse com o esforço de guerra. A WH deixou seus gerentes de fábrica decidirem se a empresa deveria produzir 
munições. Já a GE rapidamente designou um Comitê Consultivo de Defesa para integrar e agilizar os pedidos bélicos.

O oportunismo e a utopia também ameaçam a integridade organizacional. A empresa em crescimento aumenta sua complexidade. A incapacidade de lidar adequadamente com problemas cada vez mais complexos abre caminho para o oportunismo, isto é, busca de vantagens imediatas de curto prazo, e a utopia, isto é, fuga das opções difíceis, às vezes se mistura com aventureirismo, isto é, exposição da empresa inteira com base em avaliação parcial. Ao realizar análises sistemáticas de situações gerenciais complexas, a GE evitou o oportunismo e a utopia. Já a WH encarou a complexidade de forma casuística. Seus tratamentos das questões trabalhistas após a Segunda Guerra Mundial diferiram totalmente. Enquanto a GE adotou uma política dura em relação aos sindicatos, a WH manteve alternadamente relações duras e brandas. Com o desmantelamento da estrutura guarda-chuva, a falta de procedimentos sistemáticos de solução de problemas levou a WH a abraçar empreendimentos oportunistas que acabaram expondo o patrimônio da empresa, devido a análises apressadas e mal-feitas.

A falta de pessoal competente para preencher cargos gerenciais e executivos também ameaça a integridade da organização, pois ela pode enfrentar problemas de sucessão em vários níveis da sua hierarquia. De acordo com Selznick (1957 p. 57), decisões críticas da alta direção "ajudam a moldar os valores-chaves da organização”. Um desses tipos de decisão, ele sustenta, envolve o recrutamento e o treinamento de pessoal. Uma alternativa menos dispendiosa e menos consumidora de tempo é a gestão just-in-time dos recursos humanos, contratando mão-de-obra do mercado com a rapidez necessária. Embora atraente, este procedimento pode promover a fragmentação, caso os novos membros tragam consigo as próprias equipes, enfraquecendo os vínculos entre os membros da organização. Além disso, a idéia de just-in-time é ilusória, porque as pessoas precisam de tempo para se familiarizar com o ambiente organizacional, afetando, portanto, a produtividade. Finalmente, a má gestão dos recursos gerenciais pode trazer problemas de sucessão gerencial. Desde cedo, os líderes da GE perceberam a sua importância, e a empresa implementou sistemas cada vez mais abrangentes, que estimam as necessidades gerenciais e planejam a progressão na carreira em todos os níveis da hierarquia. Em várias ocasiões, a gestão inadequada dos recursos gerenciais comprometeu a continuidade da existência da WH. Por exemplo, ao morrer o sucessor de George Westinghouse, a empresa levou quase dois anos para achar substituto. Cerca de 60 anos depois, a WH levou vários meses para substituir o CEO, que se havia afastado.

Os bons resultados, sob o manto protetor da estrutura guarda-chuva, neutralizaram a maioria das ameaças à integridade da WH. Em primeiro lugar, 
os resultados generosos mais do que compensavam a incapacidade da WH de explorar plenamente as vantagens da escala e escopo, devido à sua fragmentação. Além disso, embora a coordenação inadequada prejudicasse o ritmo de crescimento da empresa, sua posição privilegiada no setor estruturado proporcionava espaço suficiente para expansão. Finalmente, o formato guardachuva simplificava e estabilizava as relações no setor, reduzindo a complexidade para todos os protagonistas, à exceção da GE.

\section{Conclusão}

A análise comparativa das histórias da General Electric e da Westinghouse lançou algumas luzes sobre a sobrevivência organizacional como propriedade dinâmica da empresa. Os fundamentos teóricos sugerem três requisitos para cultivar a propensão organizacional à autoperpetuação: renovação organizacional, desempenho excepcional e preservação da integridade organizacional. Os resultados empíricos indicam que o cultivo da propensão organizacional à autoperpetuação é afetado por traços organizacionais desenvolvidos cedo, e que a incapacidade de desenvolver traços autoperpetuantes abre caminho para a autodestruição da empresa. A análise comparativa detectou comportamentos persistentes de cada empresa no decorrer de doze décadas, comportamentos que foram sistematicamente diferentes, quando as duas empresas foram comparadas.

É preciso certa cautela em relação a algumas noções aqui apresentadas. A abordagem da integração para lidar com a diversidade não deve ser confundida com a exclusão da autonomia. Os esforços continuados para desenvolver internamente recursos gerenciais não implicam que não se possa, ocasionalmente, recrutar elementos externos. A abordagem sistemática para a resolução de problemas não deve transformar-se em situação de paralisia pela análise (Langley, 1995). Finalmente, forte coordenação da alta administração não deve implicar tirania da programação estratégica (Mintzberg, 1994).

Os comportamentos persistentes identificados ao longo da história das duas empresas forneceram explicações plausíveis, embora incompletas, para os diferentes destinos da General Electric e da Westinghouse. São necessárias pesquisas adicionais para verificar, elaborar e retificar as idéias aqui apresentadas. Estudos comparativos semelhantes poderiam verificar e enriquecer os insights teóricos apresentados neste artigo, aprimorando e aprofundando a compreensão do crescimento, da dominância e do declínio das organizações.

\section{Artigo recebido em 22.07.2003. Aprovado em 01.12.2003.}




\section{REFERÊNCIAS BIBLIOGRÁFICAS}

ANDREWS, K. R.

The concept of corporate strategy. Homewood, IL: Richard D. Irwin, 1980.

\section{BARNARD, C.}

The functions of the executive. Cambridge, MA: Harvard University Press, 1938.

BARNEY, J. B.

Gaining and sustaining competitive advantage. Reading, MA: AddisonWesley, 1997.

\section{BUNGE, $\mathrm{M}$.}

Finding philosophy in social science. Yale: Yale University Press, 1996.

\section{BUSINESS WEEK.}

GE and Westinghouse: references from 1930 to 1947.

\section{CHANDLER, A. D.}

The visible hand. Cambridge, MA: Belknap Press, 1977.

Scale and scope. Cambrigde, MA: Belknap Press, 1990.

\section{DANIELLS, L. M.}

Studies in enterprise: a selected bibliography of American and Canadian company histories and bibliographies of businessmen. Boston, MA: Baker Library Harvard University, 1957.
EISENHARDT, K;

MARTIN, J.

Dynamic capabilities: what are they?

Strategic Management Journal, v. 21, n. 10/11, p. 1105-1121, 2000.

FLECK, D. L.

Dois motores do crescimento corporativo. Revista de Administração de Empresas, v. 43, n. 4, p.1024, out./dez. 2003.

\section{FORTUNE.}

GE and Westinghouse: references from 1930 to 1999.

GEAHIGAN, P. C.

U. S. and Canadian businesses, 1955 to 1987: a bibliography. Metuchen, NJ: The Scarecrow Press, 1988.

GENERAL ELECTRIC COMPANY.

Relatórios anuais, 1971-1999.

GOODMAN, R. S.;

KRUGER, E. J.

Data dredging or legitimate research method? Historiography and its potential for management research. Academy of Management Review, v. 13, n. 2, p. 315-325, 1988.

\section{GOTTSCHALK, L.}

Understanding history: a primer of historical method. New York: Alfred A. Knopf, 1950.

KIESER, A.

Why organization theory needs historical analyses: and how this should be performed. Organization Science, v. 5, n. 4, p. 608-620, 1994. 
KISER, E.;

HECHTER, M.

The role of general theory in comparative-historical sociology.

American Journal of Sociology, v. 97, n. 1, p. 1-30, 1991.

\section{KOCKA, J.}

In scale and scope: a review colloquium. Business History Review, v. 64, n. 4, p. 690-735, Winter 1990.

\section{LANGLEY, A.}

Between "paralysis by analysis" and "extinction by instinct". Sloan Management Review, v. 36, n. 1/4, p. 63-76, Spring 1995.

Strategies for theorizing from process data. Academy of Management Review, v. 24, n. 4, p. 691-710, 1999.

\section{LAWRENCE, B. S.}

Historical perspective: using the past to study the present. Academy of Management Review, v. 9, n. 2, p. 307-312, 1984.

MINTZBERG, H.;

WATERS, J. A.

Tracking strategy in an entrepreneurial firm. Academy of Management Journal, v. 25, n. 3, p. 465-499, 1982.

The rise and fall of strategic planning: reconceiving roles for planning, plans, planners. New York: The Free Press, 1994.

MITCHELL, B. R.

International historical statistics. 4 . ed. New York: Stockton Press, 1998.
MOODY'S .

Moody's industrial manual. Westinghouse Electric Corporation. New York, Moody's Investors Service, 1923-1996.

Moody's industrial manual. General Electric Company. New York, Moody's Investors Service, 19231997.

PENROSE, E. T.

The theory of the growth of the firm. White Plains, NY: M. E. Sharpe, 1980.

PORTER, M. E.

Competitive strategy: techniques for analyzing industries and competitors. New York: The Free Press, 1980.

From competitive advantage to corporate strategy. Harvard Business Review, v. 65, n. 3, p. 43-59, 1987.

Michael Porter on competitive strategy. Boston, MA: Harvard Business School, 1988.

\section{SCHERER, F.}

In scale and scope: a review colloquium. Business History Review, v. 64, n. 4, p. 690-735, Winter 1990.

\section{SELZNICK, P.}

Leadership in administration. New York: Harper \& Row, 1957

TEECE, D.;

PISANO, G.;

SHUEN, A.

Dynamic capabilities and strategic management.

Strategic

Management Journal, v. 18, n. 7, p. 509-533, 1997. 


\begin{tabular}{l|l} 
WESTINGHOUSE $\quad$ ELECTRIC & $\begin{array}{l}\text { YIN, R. } \\
\text { Case study research: design and } \\
\text { CORPORATION. } \\
\text { Relatórios anuais, 1971-1996. }\end{array}$ \\
& $\begin{array}{l}\text { methods. London: Sage Publications, } \\
1989 .\end{array}$
\end{tabular}

